\title{
Effect on magnetic properties of zinc doped nano ferrites synthesized by precursor or method
}

\author{
T. Anjaneyulu ${ }^{1, *}$, P. Narayana Murthy ${ }^{2}$, Sk. Md. Rafi ${ }^{1}$, \\ Sk. Bademiya ${ }^{1}$, G. Samuel John ${ }^{3}$ \\ ${ }^{1}$ Department of Physics, Narasaraopet Engineering College, Narasaraopet - 522 601, A.P., India \\ *Phone: 9160606045 \\ ${ }^{2}$ Department of Physics, Acharya Nagarjuna University, Guntur - 522 510, A.P., India \\ ${ }^{3}$ Department of Physics, Krishnamurthy Institute of Technology \& Engineering, \\ Ghatkesar - 501 301, A.P., India \\ *E-mail address: anji_abi@yahoo.com
}

\begin{abstract}
Nanocrystalline $\mathrm{Cu}-\mathrm{Zn}$ ferrites have been synthesized using precursor method. $\mathrm{Cu}-\mathrm{Zn}$ ferrites were formed at low temperature without any impurities. The particle sizes were observed to decrease from $60 \mathrm{~nm}$ to $50 \mathrm{~nm}$ with increasing non-magnetic $\mathrm{Zn}$ doping. $\mathrm{Cu}$ is used to decrease the sintering temperature. The X-ray diffraction (XRD) and IR analysis of $\mathrm{Cu}-\mathrm{Zn}$ revealed the formation of SinglePhase Spinel structure at very low annealing temperature. The particle sizes observed from XRD is very well in agreement with SEM analysis. $\mathrm{Cu}-\mathrm{Zn}$ ferrite nanoparticles were observed to be dependent on the particle size. Saturation $\left(M_{s}\right)$ and Remanence $\left(M_{r}\right)$ magnetization of ferrites increases due to the modifications occurred among the A-B, A-A and B-B interactions of Spinel structure. The Coercive force $\left(\mathrm{H}_{\mathrm{c}}\right)$ decreases with increase of $\mathrm{Zn}$ ions concentration.
\end{abstract}

Keywords: Nanoferrites; Cu-Zn ferrite; Precursor Method; Magnetic properties

\section{INTRODUCTION}

Ferrites are an important class of materials that have potential applications in integrated circuitry, transformer cores, magnetic recording etc (Suzuki, 2001 and Sugimoto, 1999). Ferrite nanoparticles have potential to replace bulky external magnets in current devices. The study of ferrite nanoparticles is of interest due to the fundamental differences in their magnetic properties compared to the bulk (Tanaka, 1999). Copper zinc ferrites crystallize in cubic spinel structure. The $\mathrm{Cu}-\mathrm{Zn}$ ferrites nanoparticles properties can be influenced by several factors such as the chemical composition, electronic configuration, ionic radius, synthesis techniques etc (Smit and Wijn, 1959). Nanocrystalline $\mathrm{Cu}-\mathrm{Zn}$ ferrite have been extensively investigated due to their potential applications in non-resonant device, radio frequency circuits, rod antennas, high quality filters, transformer cores, read/write heads for high speed digital tapes and operating devices (Pradan et al., 2008; Lamani et al., 2009). 
Copper ferrite $\left(\mathrm{CuFe}_{2} \mathrm{O}_{4}\right)$ is an interesting material and has been widely used for various applications, such as catalysts for environment (Tsoncheva et al., 2010) gas sensor (Tao et al., 2000) and hydrogen production (Faungnawakij et al., 2007).

Magnetic properties of $\mathrm{Cu}$ ferrites vary greatly with the change chemical component and cation distribution. For instance, most of bulk $\mathrm{CuFe}_{2} \mathrm{O}_{4}$ has an inverse spinel structure, with $85 \% \mathrm{Cu}^{2+}$ occupying B sites (Zuo et al., 2006), whereas $\mathrm{ZnFe}_{2} \mathrm{O}_{4}$ is usually assumed to be a completely normal spinel and $\mathrm{Zn}^{2+}$ ions preferentially occupy $\mathrm{A}$ sites while $\mathrm{Fe}^{3+}$ ions would be displaced from A sites for B sites (Yao et al., 2007). Zn-substitution results to a change of cations in chemical composition and a different distribution of cations between $\mathrm{A}$ and $\mathrm{B}$ sites. Consequently the magnetic and electrical properties of spinel ferrites will change with changing cation distribution. However, there are no reports on the synthesis and characterize of $\mathrm{Cu}-\mathrm{Zn}$ ferrites nanoparticles using oxalic acid precursor method in the literatures. Therefore, it would be interesting to synthesize $\mathrm{Cu}-\mathrm{Zn}$ ferrite nanoparticles using precursor method and to study the structural and magnetic properties.

\section{EXPERIMENTAL PROCEDURES}

Nanocrystalline $\mathrm{Cu}_{1-x} \mathrm{Zn}_{x} \mathrm{Fe}_{2} \mathrm{O}_{4}(0.2 \leq x \leq 1.0)$ was prepared by precursor method (Wickham, 1967 and Raghavender et al., 2011). All of the chemicals were analytical grade. In a typical procedure, the copper hydrate $\mathrm{Cu}\left(\mathrm{NO}_{3}\right)_{2} \cdot 6 \mathrm{H}_{2} \mathrm{O}$, zinc nitrate hydrate $\mathrm{Zn}\left(\mathrm{NO}_{3}\right)_{2} \cdot 6 \mathrm{H}_{2} \mathrm{O}$, ferric nitrate nonhydrate $\mathrm{Fe}\left(\mathrm{NO}_{3}\right)_{3} \cdot 9 \mathrm{H}_{2} \mathrm{O}$ were used as starting materials.

Stoichiometric amounts of metal nitrates were dissolved in deionized water to get clear solution. The obtained aqueous solution of metal nitrates was mixed with oxalic acid in a molar ratio ranging from 1:4 to 1:0.2. The mixture solution were moved on to magnetic stirrer and stirred for $2 \mathrm{~h}$ at room temperature. The reaction mixtures turned by varying molar ratios $1: 3$ and $1: 2$. When the molar ratio was further lowered to $1: 1$, precursor solution showed different colour shades. The resultant mixtures were evaporated on a hot plate at $150{ }^{\circ} \mathrm{C}$ for 2 $\mathrm{h}$. The obtained raw powders were thermally heat treated at $350{ }^{\circ} \mathrm{C}$ for $4 \mathrm{~h}$ to get the single phase nanocrystalline $\mathrm{Cu}-\mathrm{Zn}$ ferrites. The structural characterization of the prepared $\mathrm{Cu}-\mathrm{Zn}$ ferrite nanopowders was carried out using Philips X-ray diffraction system with Ni filter using $\mathrm{Cu}-\mathrm{K} \alpha$ radiation (wave length $\lambda=1.54 \AA$ ). The average particle size $D$ was calculated using most intense peak (311) employing the Scherer formula. The particle size and morphology was carried out using FE-SEM (model JSM-7000F) manufactured by JEOL Ltd.

Figure 1. SEM images of $\mathrm{Cu}_{1-x} \mathrm{Zn}_{x} \mathrm{Fe}_{2} \mathrm{O}_{4}$ (a) $x=0.2$ and (b) $x=1.0$ nanoparticles.
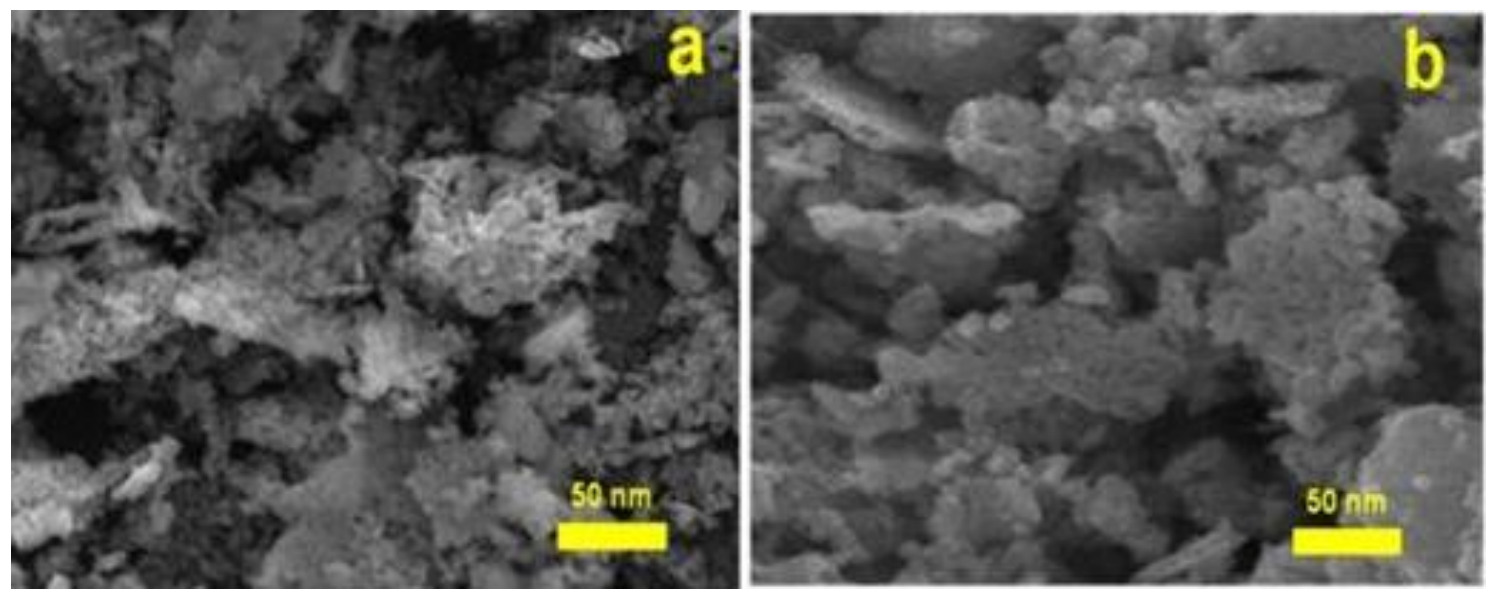
The FE-SEM was linked to an EDS/INCA 350 (energy dispersive X-ray analyzer) manufactured by Oxford Instruments Ltd. The structural changes were observed by ABB Bomem MB 102 infrared spectrometer. The samples were mixed with $\mathrm{KBr}$ and made in the form of pellets and recorded at $4 \mathrm{~cm}^{-1}$ resolution. Magnetic measurements were performed using Lakeshore VSM 7410 at room temperature with maximal applied magnetic fields of 10 kOe. Maximum magnetization, coercivity and remanent magnetization were observed from the hysteresis loops.

\section{RESULTS AND DISCUSSION}

\section{1. Magnetic properties}

Hysteresis loops for zinc substituting $\mathrm{CuFe}_{2} \mathrm{O}_{4}$ nanoferrites at room temperature are shown in Figure 2. The values of saturation magnetization $\left(M_{s}\right)$, coercivity $\left(H_{c}\right)$ and remanence $\left(M_{r}\right)$ are given in Table 1 .

The magnetic properties of $\mathrm{Cu}-\mathrm{Zn}$ nanoferrites vary with changing zinc content. The variation of magnetic properties of $\mathrm{Cu}_{1-x} \mathrm{Zn}_{x} \mathrm{Fe}_{2} \mathrm{O}_{4}$ nanoferrites can be understood in term of cation distribution and exchange interactions between spinel lattices. The $\mathrm{Cu}_{1-\mathrm{x}} \mathrm{Zn}_{\mathrm{x}} \mathrm{Fe}_{2} \mathrm{O}_{4}$ nanoferrites with $x \leq 0.6$ exhibit ferromagnetic behavior, whereas for $x=1.0$ nanoferrites display paramagnetic character with zero coercivity, zero remanence and non-saturated magnetization.

Figure 2. Hysteresis curves for the samples $\mathrm{Cu}_{1-x} \mathrm{Zn}_{x} \mathrm{Fe}_{2} \mathrm{O}_{4}(0.2 \leq \mathrm{x} \leq 1.0)$ nanoparticles.

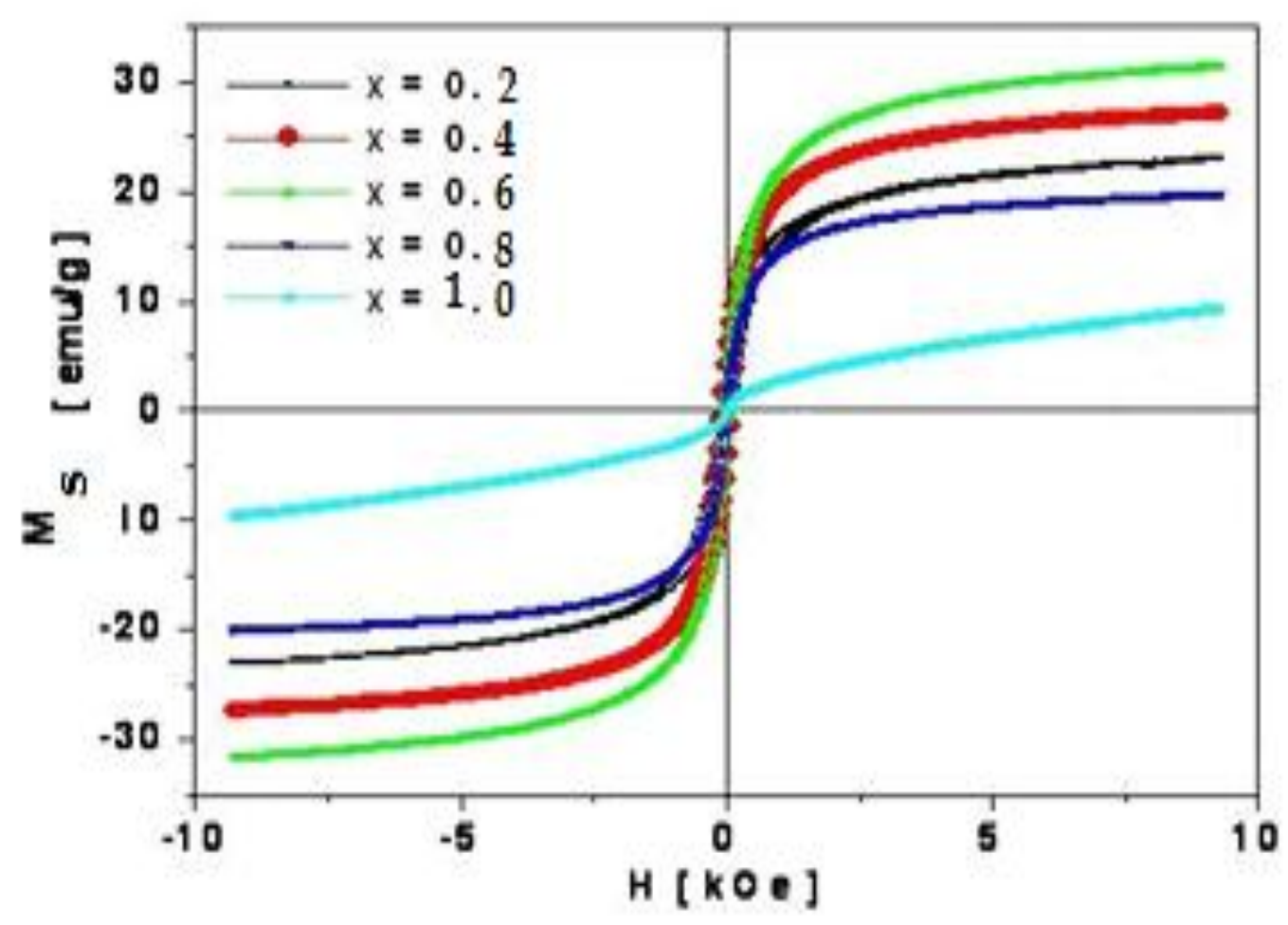


Table 1. Coercivity $H_{c}$, remanence magnetization $M_{r}$, maximum magnetization at $M$, for $\mathrm{Cu}_{1-x} \mathrm{Zn}_{x} \mathrm{Fe}_{2} \mathrm{O}_{4}(0.2 \leq x \leq 1.0)$ nanoparticles.

\begin{tabular}{cccc}
\hline $\mathbf{x}$ & $\mathbf{H}_{\mathbf{c}}[\mathbf{O e}]$ & $\mathbf{M}_{\mathbf{r}}[\mathbf{e m u} / \mathbf{g}]$ & $\mathbf{M}_{\mathbf{s}}[\mathbf{e m u} / \mathbf{g}]$ \\
\hline 0.2 & 133 & 5.9 & 26.7 \\
0.4 & 147 & 7.6 & 33.5 \\
0.6 & 95 & 6.5 & 39.5 \\
0.8 & 76 & 3.5 & 28.3 \\
1.0 & 25 & 1.2 & 10.6 \\
\hline
\end{tabular}

The saturation magnetization initially increases with increasing zinc content and reaches a maximum $(39.5 \mathrm{emu} / \mathrm{g})$ and then decreases. The increase in saturation magnetization may be attributed to the fact that, small amount of $\mathrm{Zn}$ ions substituted for $\mathrm{Cu}$ occupy A sites displaces $\mathrm{Fe}$ ions from $\mathrm{A}$ sites to $\mathrm{B}$ sites, which increases the content of $\mathrm{Fe}$ ions in $\mathrm{B}$ sites. This leads to an increase of magnetic moment in B-site and a decrease of magnetic moment in A-site. So the net magnetization increases, which is consistent with the increase of saturation magnetization. With further increase nonmagnetic $\mathrm{Zn}$ ions substitution, the dilution at the A sites increases.

This results in the breakdown of the ferromagnetic phase at $\mathrm{x} \leq 0$.6. For $\mathrm{Cu}_{1-\mathrm{x}} \mathrm{Zn}_{\mathrm{x}} \mathrm{Fe}_{2} \mathrm{O}_{4}$ $(\mathrm{x}=0.8$ and 1.0), the triangular spin arrangement on $\mathrm{B}$-sites is suitable and this causes a reduction in A-B interaction and an increase of B-B interaction. Therefore, the decrease of saturation magnetization can be explained on the basis of three sublattice model (Yafet and Kittle, 1952). As shown in Table 1 , coercivity $\left(H_{c}\right)$ continuously reduced with increasing Zn ions content. These magnetic behaviors of ferrite depend entirely on the spinel structure. For instance, normal spinel ferrite shows an antiferromagnetically ordering, while inverse spinel ferrite shows a ferromagnetic ordering. With increasing $\mathrm{Zn}$ ions concentration, a transformation from inverse spinel structure of $\mathrm{CuFe}_{2} \mathrm{O}_{4}$ ferrite to normal spinel structure of $\mathrm{ZnFe}_{2} \mathrm{O}_{4}$ ferrite wills arises gradually. Variation of saturation magnetization with $\mathrm{Zn}$ content is as shown in Figure 3.

The observed variations can be explained on the basis of cations distribution and exchange interaction between Fe ions and between $\mathrm{Zn}$ ions at the tetrahedral $\mathrm{A}$ and octahedral $\mathrm{B}$ sites. When $\mathrm{Zn}$ ions are introduced at the expense of $\mathrm{Cu}$ ions, some of the Fe ions migrate from $\mathrm{A}-$ to the B- sites. This increases the Fe ion concentration at B-sites. As a result, the magnetic moment of $\mathrm{B}$ sub-lattices increases with increasing $\mathrm{Zn}$ concentration up to $\mathrm{x} \leq 0.6$. However, as $\mathrm{Zn}$ concentration increases, the Fe ions left at A-site being small in number, the $\mathrm{A}-\mathrm{B}$ interaction experienced by B-site iron ions decreases. Also, the increased number of Fe ions at the B-site increases the B-B interaction, resulting in spin canting (Kakatkar et al., 1996). The decrease in the B sub-lattice moment, interpreted as a spin departure from colinearity, causes the effect known as canting. Magnetization values for the present $\mathrm{Cu}-\mathrm{Zn}$ nanoferrites were observed to be smaller than that of ceramically prepared samples (Sattar et al., 2005). This might be due to several reasons such as Nanocrystalline nature, surface disorder, modified cationic distribution etc. (Parvatheeswara Rao et al., 2007). 
Figure 3. Maximum magnetization values observed for $\mathrm{Cu}_{1-\mathrm{x}} \mathrm{Zn}_{\mathrm{x}} \mathrm{Fe}_{2} \mathrm{O}_{4}(0.2 \leq x \leq 1.0)$ nanoparticles from hysteresis loops.

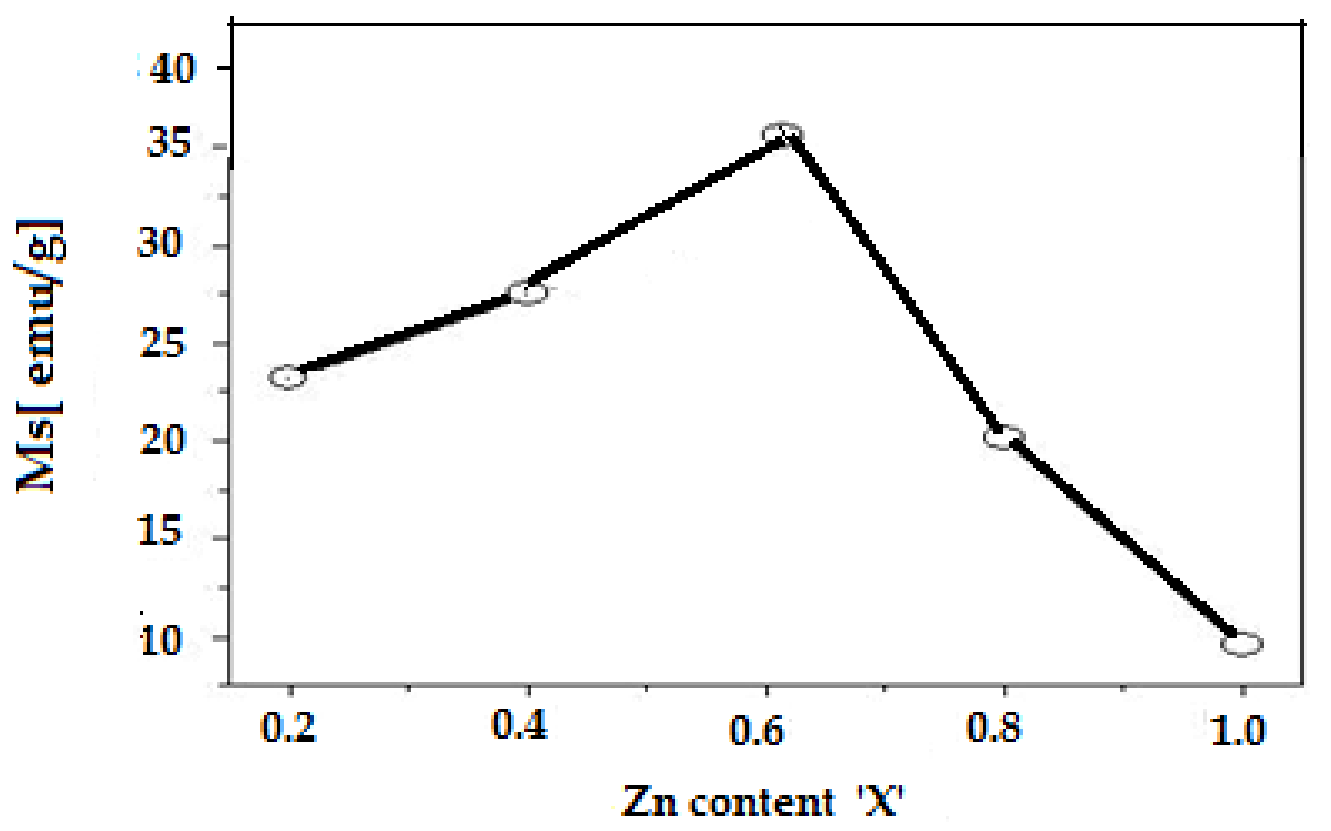

Figure 4 shows the change in the coercive force $\left(H_{c}\right)$ with $\mathrm{Zn}$ ion concentration. The coercivity is influenced by factors such as magneto crystalline anisotropy, micro-strain, magnetic particle morphology, size distribution, shape anisotropy, and magnetic domain size. The magnitude of $H_{c}$ decreases with increase in $\mathrm{Zn}$ content. This behavior is similar to that of porosity. Porosity affects magnetization process because pores work as a generator of demagnetizing field.

Figure 4. Coercivity $\left(\mathrm{H}_{\mathrm{c}}\right)$ values observed for $\mathrm{Cu}_{1-\mathrm{x}} \mathrm{Zn}_{\mathrm{x}} \mathrm{Fe}_{2} \mathrm{O}_{4}(0.0 \leq x \leq 0.8)$ nanoparticles.

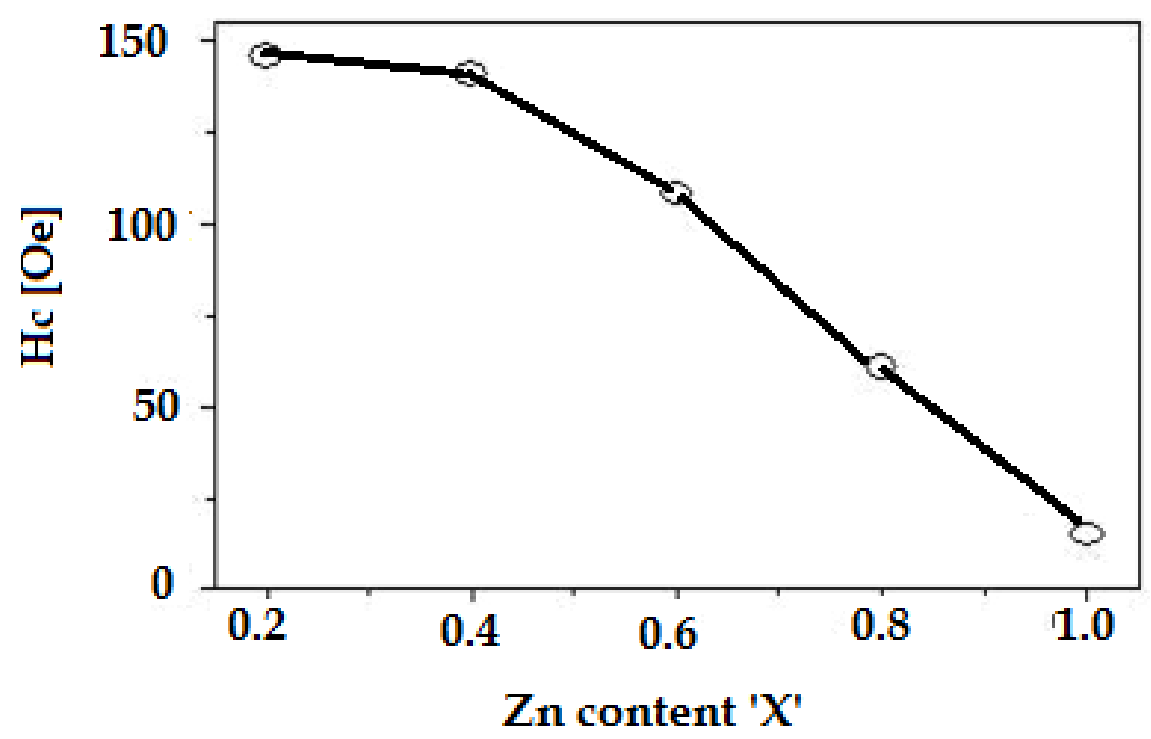


As the porosity decreases high field is needed to push the domain wall and thus Hc decreases. It is known that the coercive force has a direct relation with the anisotropy constant of the sample, and, according to the one ion model, the anisotropy field of ferrites depends on the amount of $\mathrm{Fe}$ ions in the sample (Chikazumi and charap, 1964; Coey, 1996). In the present study, it seems that the amount of $\mathrm{Cu}^{2+}$ ions decreases as a result of increase in $\mathrm{Zn}^{2+}$ content. This means that the magneto anisotropy constant decreases with increase in $\mathrm{Zn}$ content and that, consequently, the magnitude of $H_{c}$ also decreases. The observed magnetic properties of $\mathrm{Cu}-\mathrm{Zn}$ nanoferrites were due to the combined effect of reduced particle size as well as with the increase of non-magnetic $\mathrm{Zn}$ content.

\section{CONCLUSION}

A series of $\mathrm{Cu}_{1-x} \mathrm{Zn}_{x} \mathrm{Fe}_{2} \mathrm{O}_{4}(0.2 \leq x \leq 1.0)$ nanoparticles were prepared using precursor method. The XRD analysis reveals the formation of single phase spinel structure at very low annealing temperature without any secondary phases. The particle size was observed to decrease with increasing $\mathrm{Zn}$ concentration probably due to the reaction temperature and time. The lattice parameters were observed to increase with increasing $\mathrm{Zn}$ content $x$, which is due to large ionic radii of zinc when compared to copper ions. Magnetic measurements at room temperature for these samples revealed that magnetization at $\approx 1 T$ do not change monotonically with the change of $\mathrm{Zn}$ content $x$. The coercivity and remanence decreases with increasing non-magnetic $\mathrm{Zn}$ content $x$.

\section{References}

[1] Ashok R.L., Jayanna H. S., Parameshwara P., Somasekhar R., Indian Journal of Pure and Applied Physics 47(10) (2009) 715-719.

[2] Auzans E., Zins D., Blums E., Massart R., Journal Material Science 34 (1999) 1253-1260.

[3] Chikazumi S and Charap S (1964). Physics of Magnetism. John Wiley and Sons, New York, p. 140.

[4] Coey J. M. D. (1996). Rare Earth Permanent Magnetism John Wiley and Sons, $1^{\text {st }}$ edition New York, p. 220.

[5] Faungnawakij K., Tanaka Y., Shimoda N., Fukunaga T., Kikuchi R., Eguchi K., Applied Catalysis B74 (2007) 144-151.

[6] Kakatkar S. V., Kakatkar S. S., Patil R. S., Sankpal A. M., Suryawanshi S. S., Bhosale D. N., Sawant S. R., Physica Status Solidi B198 (1996) 853-860.

[7] Parvatheeswara Rao B., Caltun O., Cho W. S., Chong-Oh Kim, Cheol Gi Kim, Journal of Magnetism and Magnetic Materials 310 (2007) e812-e814.

[8] Patange S. M., Shirsath Sagar E., Toksha B. G., Jadhav S. S., Shukla S. J., Jadhav K. M., Applied Physica A95(2) (2009) 429-434.

[9] Pradhan S. K., Bid S., Gateshki M., Petkov V., Materials Chemistry and Physics 93 (2005) 224-230. 
[10] Raghavender A. T., Pajic D., Zadro K., Milekovic T., Venkateshwar Rao P., Jadhav K. M., Ravinder D., Journal of Magnetism and Magnetic Materials 316 (2007) 1-7.

[11] Raghavender A. T., Shirsath S. E., Vijaya Kumar K., Journal of Alloys and Compounds 509(25) (2011)7004-7008.

[12] Sattar A. A., El-Sayed H. M., El-Shokrofy K. M., and El-Tabey M. M., Journal of Materials Engineering and Performance 14(1) (2005) 99-103.

[13] Smit J., Wijn H. P. J., Ferrites_Philips Technical Library, Eindhoven, 1959.

[14] Sugimoto M., Journal of the American Ceramic Society 82 (1999) 269-280.

[15] Suzuki Y., Annual Review of Material Research 31 (2001) 265-289.

[16] Tanaka T., IEEE Transactions on Magnetics 35 (1999) 3010-3012.

[17] Tao S. W., Gao F., Liu X. Q., and Sørensen O.T., Materials Science and Engineering B77(2) (2000) 172-176.

[18] Tsoncheva T., Manova E., Velinov N., Paneva D., Popova M., Kunev B., Catalysis Communications 12(2) (2010) 105-109.

[19] Wickham D. G., Inorganic Synthesis 9 (1967) 152.

[20] Yafet Y., Kittel C., Physical Review 87 (1952) 290-294.

[21] Yao C. W., Zeng Q. S., Goya G. F., Torres T., Liu J. F., Jiang J. Z., Journal of Physical Chemistry C111 (2007) 12274-12278.

[22] Zuo X., Yang A., Vittoria C., Harris V. G., Journal of Applied Physics 99 08M909 (2009). 